\title{
Impact of Multimedia Package in Music on the Achivements of Music Students of +1 Class
}

Anshumati Sharma ${ }^{1}$ and Prof. Gurpreet Kaur ${ }^{2}$

\section{Introduction}

"Media arrived from the Latin word which is used in interactivity. Usually we take the media word when we talk about newspapers, magazines, radio, TV, audio-video programmes, computers etc. There are many prefixes which are commonly used with the word media such as Multimedia, Electronic media, Interactive media etc. But the most common word which is used in education is multimedia. Multimedia is a combination of text, audio, video, graphics, and animations into a single medium. This technology comprises itself different types of interactional forms such as print, radio, television, animation, photographs etc. Integration of different media multiplies the impact of a message." The means of communication is called media

According to research reports by Mayer and McCarthy (1995) and Walton (1993), "Multimedia has gained acceptance with many benefits derived from its use. Learning gains are 56\% greater, consistency of learning is $50-60 \%$ better and content retention is $25-50 \%$ higher."

\section{Definition of Multimedia}

"Multimedia is media and content that uses a combination of different content forms. The term can be used as a noun (a medium with multiple content forms) or as an adjective describing a medium as having multiple content forms. The term is used in contrast to media, which only use traditional forms of printed or hand-produced material. Multimedia includes a combination of text, audio, still images, animation, video, and interactivity content forms.

\section{Educational Benefits of Multimedia Tools}

1. Provide students with opportunities to represent and express their prior knowledge.

2. Allow students to function as designers, using tools for analyzing the world, accessing and interpreting information, organizing their personal knowledge, and representing what they know to others.

3. Multimedia applications engage students and provide valuable learning opportunities.

4. Empower students to create and design rather than "absorbing representations created by others.

5. Encourages deep reflective thinking.

6. Create personally meaningful learning opportunities.

\section{Multimedia in Music Teaching}

Music education has two parts, theory and practical. Though music is predominantly a practical subject, still the theory aspect cannot be underestimated in schools and colleges. Theory is usually taught by lecture method, which is not a very interesting and effective method of theory teaching. Fortunately, due to the advances in information technology, more effective techniques of teaching various subjects and contents are available to the teachers. Techniques like programmed learning, Team Teaching and Multimedia Packages are available which are very effective and potent in delivering the goods.

Multimedia Self-learning Packages have been developed in many contents areas and have been found to be very effective in helping the students learn the content at their own pace. Such packages are badly needed in teaching of Music so that on the one hand the pressure on the music teachers is reduced and on the other, the students of Music are able to learn various concepts of theory of music at their own pace.

\section{Review of Past Researches:}

There have been a number of studies on use of Multimedia techniques in teaching and training. All the studies have shown that Multimedia techniques not only make the teaching learning process interesting, but also very effective. Due to its nature, the students can use a multimedia package as many times as is needed, thereby learning the content more effectively. A list of some of the studies conducted in many fields is given below:

1 Research Scholar, Department of Music, Guru Nanak Dev University, Amritsar.

2 Dean, Faculty of Performing Arts, Guru Nanak Dev University, Amritsar. 
Kaur, S (2010), Effectiveness of Computer assisted instructions (CAI) in teaching of chemistry at secondary level. Singaravelu, G (2010) Multimedia assisted teaching in pedagogical technique. Raj D U (2010), Effectiveness of computer assisted learning multimedia on science achievement. Emily Donnelli, Amber Dailey, B. Jean Mandernach (2009), Toward a Philosophy of Multimedia in the Online Classroom: Aligning Multimedia Use with Institutional Goals. Guan, Y.H. (2009). A Study on the Learning Efficiency of Multimedia-Presented, Computer-Based Science Information. Gupta, Poonam Rani (2007), Multimedia in education for physically challenged persons. Alexa Joyce: (2007) UNESCO School Net ICT- based teaching and learning science, math and language in the Asia-Pacific region. Raafat George Saadé, Fassil Nebebe, and Weiwei Tan John (2007), Viability of the "Technology Acceptance Model" in Multimedia Learning Environments: A Comparative Study. Tsou, W.,(2006). Applying a multimedia storytelling website in foreign language learning. Jereb, Eva \& Branislav Smitek (2006). Applying multimedia instruction in e-learning. Matsuda, H. \& Yoshiaki Shindo. (2006). Education system using interactive 3D computer graphics (3D-CG) animation and scenario language for teaching materials. Derek A. Muller, John Eklund and Manjula D. Sharma, (2006) : The future of multimedia learning: Essential issues for research. Smeets, Ed. (2005) Does ICT contribute to powerful learning environments in primary education? Volman, M. (2005), New technologies, new differences. Gender and ethnic differences in pupils' use of ICT in primary and secondary education. Susskind, J. E. (2005): PowerPoint's power in the classroom: Enhancing students' self-efficacy and attitudes. Kawabata S, Shibuya T and Wakaki M (2005): Multi-media Directions for the Fundamental Experiments of Optics. Vegni G., N.Bergomi, and L. Cazzaniga (2005): Computers methods in Physics, a course for future teachers. A five years experience. Sutherland, Rosamund. 2004. Designs for learning: ICT and knowledge in the classroom. Carmen M. Hernández Jorge, María del Carmen Acosta Jorge, Emilio Rodríguez Gutiérrez, Eloy González García, Mar Borges Díaz, (2003) Use of the ICTs and the Perception of E-learning among University Students: a Differential Perspective according to Gender and Degree Year Group. Denice Byrne (2002) A Study of Individual Learning Styles and Educational Multimedia Preferences. Ushadevi, L(2001) Computer Aided Teaching Packages. Braak, John van. (2001) Factors influencing the use of computer mediated communication by teachers in secondary schools. Palaniappan, V.P. (1990) Effectiveness of computer assisted instruction in learning triangles. Menon M.B. (1984) Evolving a multimedia approach to teaching at post graduate level. Krishnan S.S. (1983) Development of multimedia package for teaching course on audio-visual education. Vardhini V.P. (1983) Development of multimedia instructional strategy for teaching science (Physics and chemistry) at secondary level. Ravindranath M.J. (1982) Development of multimedia instructional strategy for teaching science (Biology) at Sr. Sec. school level. Buch M.K. (1981) Effectiveness of multimedia programmed materials in the teaching of physics. Shah S.G. (1979) Development and tryout of multimedia package on effective questioning in the context of microteaching.

\section{Statement of the Problem}

Impact of multimedia package in music on the achivements of music students of +1 class

\section{Objectives}

Following were the objectives of the study:

To develop multimedia self learning instructional material on selected topics of Music Theory.

To find out the effectiveness of multimedia self learning instructional material in relation to the achievements of students of music.

\section{Hypothesis}

Following Hypothesis was tested:

There will be a significant difference in the achievement of students learning through multimedia and students taught through traditional method.

\section{Sample}

A sample of thirty students of +1 studying in school was selected randomly for the experiment. Out of these, fifteen students were put in experimental group and other fifteen formed the control group. This grouping was done randomly.

Design

Pre test -post test control group design was used.

Tools

A. Multimedia Self-learning Package B. Criterion Test

Both the tools were developed by the investigator. 


\section{Procedure}

Development of Multimedia Package

The investigator developed multimedia self learning package on the construction and playing of Tanpura, and Tabla from the syllabus of +1 .

The video recording and textual matter for training to the concepts were used for developing a multimedia package with the help of appropriate software.

This package was tried out on five students of music of +1 in order to find out any shortcomings of the package.

After this initial try out, the content and presentation of the package was modified in the light of the feedback given by the sample.

The investigator also developed a set of instructions for the experimental group on the use of multimedia package.

An Achievement test was also developed for testing the learning outcomes of the students.

\section{Experiment}

The experimental group was explained the purpose of the experiment and was given written instructions along with one C.D. containing multimedia package. The group used the C.D. individually for forty minutes every day for one week under the guidance of the local teachers and the investigator.

Before the start of the experiment both the groups were tested for their knowledge for particular theory which was selected for the developing multimedia package.

\section{Statistical Technique}

For finding out the difference in performance of both the groups, t-test was employed

\section{Analysis}

\section{Comparison of pre-test scores of Experimental and Control Groups.}

The scores obtained by the experimental and control groups were subjected to statistical treatment to determine the significance of difference between their means. Though the sample was selected randomly from a large population, still the investigator wanted to make sure that the both the groups were equal as far as their knowledge of Music was concerned. Table 4.1 gives details of the analysis.

Table 4.1:

Mean, S.D. and ' $t$ '-value of scores of experimental and control groups on pre-test

\begin{tabular}{|l|l|l|l|l|}
\hline Group & Mean & S.D. & $\mathrm{N}$ & ' $\mathrm{t}$ ' \\
\cline { 1 - 4 } Experimental & 6.13 & 1.30 & 15 & \multirow{2}{*}{$0.11 \mathrm{NS}$} \\
\hline Control & 6.33 & 0.97 & 15 & \\
\hline
\end{tabular}

$\mathrm{df}=28$. Table value of 't' at 0.05 level of confidence $=2.048$.

It is clear from Table 4.1 that the calculated value of ' $\mathrm{t}$ ' $=0.11$ is far less than the Table value of ' $\mathrm{t}$ ' even at 0.05 level of confidence. Hence ' $\mathrm{t}$ ' $=0.11$ is not significant even at 0.05 level of confidence. Thus it may be concluded that both means do not differ significantly and are equal. Therefore, it may be inferred that both the groups are equal as far as their knowledge of Music is concerned.

\subsection{Comparison of post-test scores of Experimental and Control Groups.}

Post-test scores were also subjected to statistical analysis. Table 4.2 given details of the analysis.

Table 4.2

Mean, S.D. and ' $t$ '-value of scores of experimental and control groups on pre-test

\begin{tabular}{|l|l|l|l|l|}
\hline Group & Mean & S.D. & N & 't' \\
\hline Experimental & 30.53 & 2.38 & 15 & \multirow{2}{*}{$8.39^{*}$ * } \\
\hline Control & 21.73 & 3.47 & 15 & \\
\hline
\end{tabular}

$\mathrm{df}=28$. Table value of ' $\mathrm{t}$ ' at 0.001 level of confidence $=3.67$.

It is clear from Table 4.2 that the calculated value of ' $\mathrm{t}$ ' $=8.39$ is far more than the Table value of ' $\mathrm{t}$ ' at 0.001 level of confidence. Hence ' $\mathrm{t}$ ' $=8.39$ is highly significant at 0.001 level of confidence. Thus, it may be concluded that both means do differ significantly, hence both the groups differ significantly in their achievement of selected concepts of Music. 
On the perusal means, it is clear that the mean of experimental group (30.53) is higher than the mean of control group (21.73). Hence, it may be concluded that experimental group performed better than the control group on the achievement test. This leads to the inference that Multimedia Package was more effective than the traditional method of teaching Music to the school children.

\section{Delimitation}

Study was be limited to +1 students and only girl students were selected in the sample.

\section{Main Findings}

It was hypothesized that there will be a significant difference in the achievements of students learning through multimedia and students taught through traditional method.

After the analysis of data it is found that there exists significant difference in the achievement of students studied through self learning multimedia package than the the students studied through traditional method of study.

The mean of achievement score of students studied through multimedia was 30.53 and mean of achievement score of students studied through traditional method was 21.73 , which reveals that teaching through multimedia gave better result.

Therefore it can be concluded that Multimedia based Self-Learning package has significant effect on the achievement of students.

\section{Conclusion}

The present study has substantially that self learning multimedia package significantly improves the performance and learning achievement of the students in Music.

In present time the computer has been introduced at the school level and teacher should use computer as a medium for instructions in classrooms.

With the help of computers and internet the students get freedom to collect any type of information whether quantitative or qualitative.

The students get exposed to a new atmosphere in which they can interact with specific self learning multimedia packages by learning on their pace. It will help the students to improve his/her composition and presentation skills.

Study concludes that technology based learning effects positively on students' attitude towards learning, self-confidence and self-esteem.

Thus it may be said that multimedia technique of teaching a subject like Music is far more effective than the traditional teaching methods. Music being a performing subject, multimedia can present before students a variety of ways to understand various concepts of Music in a more effective and interesting manner.

\section{Bibliography}

Bennett, Bell., Dacio, Heidi., Logan, Tillie., Rousseau, Mark Smith. And Srathman, Krishna. (2009). Video Instruction Versus Traditional Lecture Recalling Simple Steps. An Unpublished Project of Master of Arts in Education. Faculty of California State University.

Braian, ferry. and Brown, Christine. (1995). Technology in Teacher Education Using Multimedia to Enhance the Design and make Processes. An Article Published online in Australian Journal Of Teacher Education. Volume 20/issue 2.

Cheng, Iren. and Vient Safant, Uuis. 2010. Multimedia In Education Adapting Learning and Testing. World Scientific Publishing.

Hegge, Jennifer. (1995). Multimedia Education. An unpublished Honors Thesis .Ball State University Muncie, Indiana.

Iron Cheng, Lluis Vicent Safont, Anup Basu. (2010) Multimedia in education adaptive, learning and testing.

Ivers, Kerens. and Barron, Anne. Multimedia Projects in Education (Designing, Producing and Assessing) Second edition. Library of Congress Cataloging In Publication Data.

Koumi, Jack. (2006). Designing Video and Multimedia For Open and Flexible Learning. Routledge Taylor and Francis Group.

M.Jarz, Ewald. (1998), Theoretical aspects of Multimedia Education. An Abstract Taken from DESIDOC Bulletin of Information Technology, vol. 18 , no. 6, Nov, pp- 5- 23.

Muller, Derek Alexander. (2008). Designing Effective Multimedia For Physics Education. An unpublished Ph.D. Thesis. School of Physics, University of Sydney Australia.

P.Curtin, Dennis., Foley, Kim., Sen, Kunal. And Morin, Cathleen. (1999). Information Technology (The Breaking Wave). Tata MCGRAW- Hill Edition. 
Rao, K.R., S. Bojkovic, Zoran and A. Milovanic, Dragorad. (2008). Multimedia Communication Systems (Techniques, Standards and Network) Third Impression, Dorling Kindersley Publisher (India) Pvt. Ltd.

Richard Albarino. (1966) "Goldstein's LightWorks at Southhampton," Variety, August 10. Vol. 213, No. 12.

Tennet, Lee. (2003). Multimedia: Perceptions and use in Preservice Teacher Education. An unpublished Ph.D. Thesis. Center for Innovation in Education Queensland University of Technology Brisbane, Queensland, Australia.

Vaughan, Tay. (1993), Multimedia: Making It Work (first edition, ISBN0-07-881869-9), Osborne / McGraw-Hill, Berkeley, pg. 3.

Villamil, John. and Louis Molina, Casanova. (1998). Multimedia (an Introduction), Prentice Hall of India Private Limited.

Journals and Magazines

Luann K. Stemler, Journal of Educational Multimedia and Hypermedia, Volume 6, Issue 3-4, 1997.

PC World magazine (October1993). "Ten Reasons to Use Multimedia in Education.

\section{Websites}

www.wikipidea.multimedia.com

www.cemca.org.com/emhandbook/section1-8

www. tech4learning.com

http://people.ucalgary.ca/ edtech/688/hist.htm

http://webserver.ignou.ac.in/institute/handbook5/Section\%203.pdf 